\title{
INITIAL TEST WELL CONDITIONING AT NOPAL I URANIUM DEPOSIT, SIERRA
} PEÑA BLANCA, CHIHUAHUA, MEXICO

R. D. Oliver (LANL), J. C. Dinsmoor (LANL), S. J. Goldstein (LANL), I. Reyes (UACH), and R. de la Garza (UACH)

Three test wells, PB-1, PB-2, and PB-3, were drilled at the Nopal I uranium deposit as part of a natural analogue study to evaluate radionuclide transport processes during March-April 2003. The initial pumping to condition the wells was completed during December 2003. The PB-1 well, drilled immediately adjacent to the Nopal I ore body, was continuously cored to a depth of $250 \mathrm{~m}$, terminating $20 \mathrm{~m}$ below the top of the measured water level. The PB-2 and PB-3 wells, which were drilled on opposite sides of PB-1 at a radial distance of approximately 40 to $50 \mathrm{~m}$ outside of the remaining projected ore body, were also drilled to about $20 \mathrm{~m}$ below the top of the measured water level. Each test well was completed with 4-inch (10.2-cm) diameter PVC casing with a slotted liner below the water table. Initial conditioning of all three wells using a submersible pump at low pump rates [less than 1 gallon $(3.81)$ per minute] resulted in measurable draw down and recoveries. The greatest drawdown $(\sim 15 \mathrm{~m})$ was observed in PB-2, whereas only minor $(<1 \mathrm{~m})$ drawdown occurred in PB-3. For PB-1 and PB-2, the water turbidity decreased as the wells were pumped and the $\mathrm{pH}$ values decreased, indicating that the contamination from the drilling fluid was reduced as the wells were conditioned. Test wells PB-1 and PB-2 showed increased inflow after several borehole volumes of fluid were removed, but their inflow rates remained less that the pumping rate. Test well PB-3 showed the smallest drawdown and least change in $\mathrm{pH}$ and conductivity during initial pumping and quickest recovery with a rise in measured water level after conditioning. The 195 gallons (750 1) of water pumped from PB-3 during conditioning was discharged through a household sponge. That sponge showed measurable gamma radiation, which decayed to background values in less than 12 hours. Preliminary interpretations include filtration of a radioisotope source with a short half-life or of a radioisotope that volatized as the sponge dried, such as Rn-222 and its short-lived daughters. No filtration was used during the pumping of PB-1 or PB-2. 